\title{
MODALITETI SAMOPROCENE U UDŽBENICIMA FRANCUSKOG KAO STRANOG JEZIKA NA NIVOU A1
}

\begin{abstract}
U našem radu istražili smo u kojoj meri i u kojem obliku određeni udžbenici za učenje francuskog kao stranog jezika podstiču učenika na samoprocenu (autoevaluaciju). Opredelili smo se za tri udžbenika stranih izdavača čiji je krajnji ishod nivo A1 Zajedničkog evropskog okvira imajući u vidu preporuke savremenih autora da je samoprocena veština koju učenik osvešćuje postepeno, od samog početka učenja. Prvi deo rada bavi se teorijskim okvirom učeničke samoprocene, dok drugi deo predstavlja istraživanje korpusa. Naša analiza je pokazala da sva tri udžbenika podstiču metakogniciju u nekom obliku, ali da je samo jedan od njih usmeren na razvijanje učeničke samoprocene i tzv. „znanja o sebi“. Stoga smo detaljno ispitali modalitete samoprocene koje nudi pomenuta knjiga. Zaključujemo da bi udžbenici stranog jezika trebalo da u mnogo većoj meri podstiču učenika na samorefleksiju i samoprocenu.
\end{abstract}

Ključne reči: samoprocena, autoevaluacija, udžbenici francuskog kao stranog jezika

\section{Uvod}

Učenička samoprocena predstavlja veoma važan segment evaluacije. Brojni autori naglašavaju koliko je važno da nastavnici podele teret ocenjivanja sa učenikom. Međutim, kako Žiropađa navodi, u kontekstu učenja/nastave stranog jezika ne postoji dovoljan broj istraživanja na ovu temu (Žiropađa, 2008: 24), što je pokazala i metaanaliza grčkih autorki (Papanthymou \& Darra, 2019: 59-61). U domaćoj literaturi, dve autorke su se bavile samoprocenom u udžbenicima stranog jezika. Jedna autorka se bavila različitim udžbenicima ruskog jezika (Кончаревић, 2006; Кончаревић, 2008), a druga je analizirala francuske za niže razrede osnov-

*_jelena.stojanovic93@outlook.com. 
ne škole (Вујовић, 2016); obepodvlače da je samoprocena u udžbenicima oblast koju još uvek treba unapređivati i ispitivati (Кончаревић, 2006: 14; Вујовић, 2016: 349).

U prvom delu rada bavićemo se samoprocenom kroz teorijsku prizmu. Pre svega, nastojali smo da rasvetlimo sve ono što se krije u ,terminološkoj džungli“" o kojoj govori Kristina Taglijant (Vandevelde, 1982: 149; in Taglijant, 2009: 8). Odgovorićemo na pitanje zašto je samoprocena važna i otkud njeno mesto u udžbenicima stranog jezika. Takođe, bavićemo se metakognicijom, psihološkim konceptom za koji se samoprocena neraskidivo vezuje. Najzad, utvrdićemo u kojim trenucima i pomoću kojih instrumenata se samoprocena može sprovoditi.

Drugi deo rada predstavlja istraživanje koje se bavi trima udžbenicima francuskog jezika za odrasle i starije adolescente čiji je krajnji ishod nivo A1. Imajući u vidu tvrdnje savremenih autora da je samoprocena veština koja se uči postepeno (Ross, 2006: 9; Вујовић, 2009: 103; Panadero et al., 2016b: 322) želeli smo da ispitamo u kojoj meri prvi po redu udžbenik tog stranog jezika pomaže učeniku da tu veštinu osvesti, izgradi i iskoristi je za svoj napredak u učenju.

\section{Osnovne definicije}

\subsection{Samoprocena}

Autoevaluaciju bismo na najjednostavniji način mogli definisati kao učenikovo intrinzično ocenjivanje sopstvenih postignuća. Međutim, postoji kompleksan terminološki problem. Naime, brojni autori koriste najrazličitije termine, a pritom ne preciziraju u kojoj meri su oni sinonimni: samoevaluacija (Вујовић, 2016; Žiropađa, 2008), samoocenjivanje (Кузмановић \& Павловић Бабић, 2011: 78), auto-évaluation (,autoevaluacija“) i auto-estimation („samoprocena“) (Taglijant, 2009), self-assessment (Ross, 2006) i self-evaluation. Panadero i Alonso-Tapija preciziraju da potonji engleski termin označava davanje brojčane ocene, a da su mu sinonimi : self-rating, self-grading ili self-marking (2013: 556-557). Nasuprot tome, termin self-assessment za njih označava čitav spektar mogućnosti koje spadaju u domen kvalitativne (a ne samo kvantitativne) procene (ibid., 556). U srpskoj terminologiji tu razliku izražavaju reči ocenjivanje i procenjivanje (Pešikan \& Antić, 2016: 9). Takođe, da bi se odagnala ter- 
minološka zamagljenost, spomenimo još jednu razliku koju smo našli u srpskoj pedagoškoj literaturi. Kako navode Pešikan i Antićeva, termin procena/procenjivanje odnosi se na učenika u kontekstu učenja i savladavanja gradiva, dok se izrazi vrednovanje i evaluacija primenjuju na nastavni proces i kvalitet rada nastavnika ili programa (ibid., 9). U našem radu koristićemo termin samoprocena, ali ćemo, iz praktičnih razloga, njegovim sinonimom smatrati reč autoevaluacija.

Postoji mnoštvo sličnih definicija samoprocene, a Panaderova nam se čini najsveobuhvatnijom. Naime, ovaj autor učešće učenika smatra za conditio sine qua non i više pažnje poklanja nekim manje očiglednim aspektima: „Samoprocena je kvalitativna procena procesa učenja i njegovog krajnjeg proizvoda, koja počiva na unapred ustanovljenim kriterijumima" "1 (Panadero, 2011: 78; in Panadero \& Alonso-Tapia, 2013: 556). Ipak, važno je napomenuti da se ovaj fenomen može posmatrati iz više perspektiva. Panadero i Alonso-Tapija stoga podvlače da samoprocena može biti strategija učenja ili pak pedagoška (nastavnička) strategija. U prvom slučaju inicijator je sam učenik, te se ova perspektiva vezuje za teoriju samoregulisanog učenja (engl. self-regulated learning). U drugom slučaju podsticaj daje nastavnik.Stoga ga ovi autori smatraju načinom formativne procene (Panadero \& Alonso-Tapia, 2013: 554). Ako se osvrnemo na samoprocenu kao strategiju učenja, pomenimo još mišljenje Vujovićeve (sa kojom se ne moramo nužno složiti) koja bitnom karakteristikom smatra njenu ,sveprisutnost u procesu nastave i učenja“ (2009: 104). Ova autorka takođe zapaža: „Samoevaluacija se, zapravo, vrši stalno, svesno ili nesvesno, jer niko ne može nešto učiti, a da ne zna da li njegova postignuća odgovaraju onome što je želeo da postigne i da li napreduje ka cilju koji je sebi postavio“ (ibid.). Premda ne smatramo da je sposobnost samoprocene uvek osvešćena kod učenika, slažemo se sa onim što Vujovićeva implicitno zaključuje - da je neraskidivo vezana za nivo metakognicije.

Kako Žiropađa navodi, koncept samoprocene počiva na Maslovljevoj humanističkoj psihologiji i pojmu samoaktualizacije (2008: 15-16). Takođe, usko je povezan sa pojmom učeničke autonomije, koja se definiše kao „sposobnost preuzimanja odgovornosti za sopstveno učenje“ (Holec, 1979: 3; in Дурбаба, 2011: 219). Iz pedagoške perspektive, autoevalua-

$1 \quad$ Naš prevod sa engleskog. 
cija se smatra „krunom“ autentičnog procenjivanja. Naime, reč je o načinu procene koji počiva na ,interpretativnoj paradigmi i [...] kvalitativnoj metodologiji“ (Кузмановић \& Павловић Бабић, 2011: 75). U svetlu ove paradigme, samoprocenu bismo mogli opisati kao učenikovu interpretaciju sopstvenog napretka/nazadovanja u učenju. Najzad, Zajednički evropski okvir za žive jezike $e^{2}$ takođe ukazuje na korisnost samoprocene. Ta tendencija ilustrovana je kroz skale samoprocene za svaki nivo koje se nalaze u samom ZEOJ-u (2002: 295-306).

\subsection{Zašto je samoprocena važna?}

U prethodnom poglavlju videli smo da samoprocena u učenju stranog jezika počiva na izuzetno bogatoj interdisciplinarnoj teorijskoj osnovi, te da zahteva znanja iz dokimologije, pedagoške psihologije i glotodidaktike. Imajući to u vidu očigledno je koliko je ova tema kompleksna. U nastavku ćemo se baviti nekim gorućim pitanjima u oblasti samoprocene. Pre svega, Končarević navodi da „,[r]ealizovanje autokontrolne, autokorektivne i autoevaluacione funkcije udžbenika stranog jezika [...] predstavlja bitan parametar kvaliteta njegovog didaktičkog oblikovanja“ (Кончаревић, 2008: 55).

Brojni autori podvlače značaj samoprocene. Recimo, Veltšef i Ilton bilo koju formu evaluacije smatraju neophodnom pratiljom učenja: "[O] na mora pomoći i omogućiti svakom učeniku da spozna svoj profil učenja. Stoga, deo evaluiranja može i mora biti delegiran učeniku $u^{366}$ (Veltcheff \& Hilton, 2003: 141). Takođe, ona predstavlja ,proširenje evaluacionog spektra“" (Oscarsson, 1989; in Blue, 1994: 3), odnosno donosi potrebno „osveženje“ u inače ustaljenu lepezu evaluacionih modaliteta. Osim toga, pomenimo mišljenje grupe autora koji je smatraju ključnim vidom evaluacije jer ,angažuje sva tri domena samoregulisanog učenja: kognitivni, motivacioni i afektivni“" (Paris \& Paris, 2001: 95; in Panadero \& Alonso-Tapia, 2013: 559). Prateći istu nit, možemo reći da je ona, za razliku od drugih načina (pr)ocenjivanja, povezana sa svim aspektima učenikove ličnosti.

2 U daljem tekstu koristićemo siglu ZEOJ.

3 Naš prevod sa francuskog.

$4 \quad$ Naš prevod sa engleskog. 
Još se krajem osamdesetih godina prošlog veka pisalo o preimućstvima učeničke samoprocene. Blu navodi njene tri strane koje Dikinson smatra izuzetno pozitivnim (Dickinson, 1987; in Blue, 1994: 3). Zahvaljujući njoj učenici uče kako da budu autonomni, a u isti mah, nastavnik dobija vreme da se pozabavi nekim drugim aspektima učenja i nastave. Najzad, zaključuje se da samoprocena implicira potonji napredak u učenju. Poslednji aspekat koji smo naveli već dugo muči istraživače. Još jedno zanimljivo i još uvek otvoreno pitanje tiče se njene validnosti. Prema uvreženom mišljenju, učenikova samoprocena je validna ako je ista kao procena iz ugla nastavnika. Ros ipak donosi drugačiji, humaniji pogled na pitanje validnosti i, prema našem mišljenju, ,spašava“ ovaj koncept. Naime, on smatra da je samoprocena validna samo ako ima pozitivne posledice, odnosno, ako doprinosi napredovanju u učenju (Ross, 2006: 4). Očekujemo da ova perspektiva validnosti samoprocene bude prisutna u našem korpusu.

\subsection{Metakognicija}

Metakogniciju je najjednostavnije definisati kao ,mišljenje o sopstvenim mislima“ (Kankaraš, 2004: 151). Zbog širine ove teme, u našem radu se, nažalost, ne možemo baviti svim aspektima metakognicije i njenom problematikom koja zaokuplja psihologe. Pomenimo samo neke njene elemente:

1. ,znanje o sopstvenom (ili uopšte, ljudskom) kognitivnom funkcionisanju, o njegovim karakteristikama, moćima i ograničenjima““

2. „strategije praćenja i upravljanja sopstvenom kognicijom i ponašanjem"

3. ,subjektivn[i] doživljaj[i], odnosno metakognitivna iskustva koja izviru iz nekih promena ili privremenih teškoća u kognitivnom funkcionisanju (npr. zbunjenost, osećaj da nam je nešto „na vrh jezika“, osećaj znanja nečega itd.)“(Kankaraš, 2004: 150-151, prema Kovač-Cerović, 1996)

4. komponenta koju Kankaraš ne navodi u opštoj klasifikaciji, ali napominje da spada u domen metakognicije - metamemorija, ,svest o sopstvenom pamćenju“" (Kankaraš, 2004: 154)

Iz ovog kratkog pregleda može se uvideti veza samoprocenjivačke prakse sa razvojem metakognitivnih sposobnosti. Analizom korpusa pokušaćemo da utvrdimo da li i u kojoj meri udžbenici neguju metakognitivno 
osvešćivanje kroz modalitete samoprocene. U našem ispitivanju biće nam dragoceni parametri koje je opisala Končarević. Naime, ona je ispitivala korpus udžbenika ruskog kao stranog jezika proučavajući u njemu tri vrste metaznanja. Za naše istraživanje najrelevantniji je onaj tip koji Končarević naziva „znanjima o sebi““ (2006: 11-12). Autorka zaključuje:

Уџбеник би, ради постизања прецизније слике код ученика о успешности у достизању наставних циљева, требало да садржи скалу за самопосматрање, самопроцену, самоевалуацију. Тако би ученик могао не само да утврди какво је његово знање, него и да стекне представу о томе какво би могло да буде, те да, пратећи своје напредовање, истовремено управља начином рада и учења, уносећи потребне измене у своју стратегију (Кончаревић, 2006: 11).

Autorka je takođe uočila da udžbenici ne podstiču i ne upućuju adekvatno učenika na samokorekciju, što smatra velikim nedostatkom (ibid., 12). Ovo zapažanje nam je važno jer ukazuje na pojam samokorigovanja koji je usko vezan za samoprocenu, ali kojem se ne poklanja dovoljno pažnje. Uostalom, u glotodidaktičkoj literaturi mali broj radova je posvećen pitanju korekcije uopšte.

Druga dva tipa metaznanja nisu eksplicitno vezana za samoprocenu, ali su važna zbog aparature samog udžbenika, te ćemo se osvrnuti i na njih. Prvi tip kojim se Končarević bavi jesu „znanja o zadatku“, a reč je o paratekstualnim elementima udžbeničke tekstoteke: sadržaju, najavi ${ }^{5}$ lekcija i nalozima samih zadataka i aktivnosti (ibid., 8-11). Iako se na prvi pogled čini da uvodna strana lekcije ili sadržaj udžbenika nemaju dodirnih tačaka sa samoprocenom, oni predstavljaju važan metakognitivni element. Naime, danas se smatra da je samoprocena kvalitetno sprovedena ako su učenici prethodno upoznati sa kriterijumom procenjivanja. Tako istraživači naglašavaju da učenici moraju poznavati ,pravila igre“, bilo da ih je ustanovio sam nastavnik, ili da su ih konstruisali u saradnji (Panadero \& Alonso-Tapia, 2013: 557-558). Budući da u slučaju našeg istraživanja ne možemo imati uvid u kriterijume koje daju akteri procesa nastave/učenja, posmatramo udžbenik kao jedini izvor kriterijuma i smernica koje učenici

$5 \quad$ Končarević za ovaj element koristi termin anons i definiše ga kao kratak pregled sadržaja lekcije (2006: 9). 
dobijaju. Stoga su važni paratekstualni elementi čija je funkcija da najavljuju delove gradiva koji će biti obrađeni. Oni sadrže implicitne funkcije samoprocene i služe učeniku kao orijentir.

Poslednji tip metaznanja kojima se bavi Končarević jesu „znanja o strategijama“ koja imaju „specifičnu didaktičku namenu - pomaganje učeniku u izgrađivanju navika i umenja samoučenja, samokontrole i efikasnog služenja školskom knjigom“ (Кончаревић, 2006: 12-13). Konkretan primer bili bi praktičnisavetiza usvajanje neke veštine ili pojma - recimo, za poboljšanje pisane produkcije. Te instrukcije bi trebalo ne samo da učeniku pomognu u usavršavanju, već i da ga posredno podstaknu na samorefleksiju.

\subsection{Kada se samoprocena sprovodi?}

Samoprocena je zanimljiva i zbog toga što se može sprovoditi na svim nivoima učenja jezika, na svim jezičkim veštinama (usmene ili pisane aktivnosti razumevanja pročitanog, razumevanja na sluh, produkcije, interakcije i medijacije), u bilo kojoj fazi učenja. Proučavajući korejske učenike u kontekstu engleskog kao stranog jezika, Batler i Li su dali svoje viđenje vremenskih odrednica za samoprocenjivanje. Naime, oni su napravili razliku između kontekstualizovane samoprocene, koja se odvija neposredno nakon obavljenog zadatka i direktno se odnosi na njega, i one koja je (u manjoj ili većoj meri) dekontekstualizovana, jer se odnosi na neku učenikovu opštu kompetenciju (Butler \& Lee, 2006: 508). Očigledna je terminološka paralela sa Braunom i Harisom (Brown \& Harris, 2013: 370) koji smatraju da samoprocena može biti globalna (Batler i Li je nazivaju dekontekstualizovanom) i specifična (kontekstualizovana kod Batlera i Lija).

Osvrnimo se još jednom na fenomen metaznanja. Kada govori o „znanjima o sebi““, Končarević navodi mesta u udžbeniku na kojima se autoevaluacione funkcije realizuju:

$[И]$ ницијална провера напочетку уџбеника, на основу које би се дијагностификовало да ли ученик има довољно основе и предзнања да прати градиво које следи; финални тест, на основу којег би ученици могли да провере своје знање; рекапитулациони тестови на крају већих уџбеничких целина, који би послужили и као оријентир за благовремени корективни рад (Кончаревић, 2006: 12). 
Klasifikacija Končarevićeve uglavnom se poklapa sa onim što Panadero i saradnici uočavaju. Međutim, potonji autori smatraju da, pored dijagnostičke funkcije i procene finalnog produkta, samoprocena može imati vodeću ulogu u svim etapama učenja. Oni navode poznat Cimermanov (Zimmerman \& Moylan, 2009; in Panadero \& Alonso-Tapia, 2013: 555) trodelni model samoregulisanog učenja koji se sastoji iz planiranja (engl. forethought), realizacije (engl. performance) i samorefleksije (engl. selfreflection $)^{6}$, te da samoprocena može i mora da se odvija i u centralnoj fazi učenja (Panadero \& Alonso-Tapia, 2013: 557).

Takođe nas interesuju načini integracije autoevaluacionih sadržaja unutar udžbeničke tekstoteke. Na našem korpusu analiziraćemo da li su autoevaluacione celine jasno izdvojene od ostalih komponenti metode. Problem njihove pozicije je mač sa dve oštrice. S jedne strane, očiglednim izdvajanjem samoprocena ne čini kompaktnu celinu sa ostalim sadržajima sa kojima se učenik susreće čitajući udžbenik. S druge strane, ako su pozivi na samoprocenu suviše suptilni, postoji opasnost da čitalac ne obrati pažnju na njih i tako ne realizuje pun didaktički potencijal knjige. Ukoliko su stranice posvećene samoproceni štampane na samom kraju udžbenika, takođe postoji velika verovatnoća da će ih učenici jednostavno preskočiti ili da se do njih ni neće stići.

Kada govorimo o vremenskim indikatorima samoprocene, treba napomenuti da se radi o veštini koja zahteva vreme i obuku:

Вештина самоевалуације се постепено учи и развија у току процеса наставе/учења на свим нивоима и у свим узрастима, почев од лакших задатака (уочавање грешака у читању, прегледање диктата и сл.) до коришћења разних унапред договорених критеријума вредновања и процењивања [...] (Вујовић, 2009: 103).

Panadero i Alonso-Tapija podvlače koliko je neophodno da nastavnik eksplicitno podučava učenike autoevaluaciji (2013: 570). Na to bismo se nadovezali mišljenjem da je i samom nastavniku potrebna obuka. Imajući to u vidu, smatramo da udžbenik može predstavljati veoma moćno sredstvo i pružati dragocene smernice.

$6 \quad$ Naši prevodi sa engleskog. 
MODALITETI SAMOPROCENE U UDŽBENICIMA FRANCUSKOG ...

\subsection{Instrumenti samoprocene}

U najopštijem smislu, instrumenti za samoprocenu dele se u tri grupe (u zavisnosti od stepena njihove strukturiranosti), koje navode Bertoćini i Kostanco. Spontane forme su one koje nisu strukturirane, već intuitivne. Autorke kao primer navode slučaj kada učenik poredi svoj učinak sa nekim modelom. U polustrukturiran tip spadaju dnevnik učenja i portfolio, dok su potpuno strukturirane forme skale i upitnici (Bertocchini \& Costanzo, 2017: 228).

Smatramo da treba napraviti razliku između portfolija kao zbirke učeničkih radova s jedne strane i udžbeničkog konstrukcijskog rešenja sa druge strane. Obe vrste portfolija spadaju u autoevaluacione instrumente, ali za naše istraživanje važan je samo onaj koji je inherentan udžbeniku. Udžbenički portfolio obično je rađen po ugledu na Evropski jezički portfolio i osmišljen je tako da podstiče učenika na samorefleksiju, ali i na promišljanje o jeziku koji uči, stoga može posedovati i kontekstualizovanu i dekontekstualizovanu samoprocenu. Imajući to u vidu, smatramo da bi udžbenički portfolio trebalo da pokazuje veliki stepen strukturiranosti. Kada se uzme u obzir priroda i funkcija samog udžbenika, naša hipoteza je da će on sadržati strukturirane instrumente samoprocene.

Panadero i saradnici podsećaju da se sprovođenje samoprocene može vršiti pismenim ili usmenim putem (Panadero et al., 2016a: 9). Mi bismo tu dodali i procenu pomoću kompjutera (npr. putem platforme „Mudl“).

Zanimljivo je da samoprocena može, po potrebi, uključivati više aktera. Recimo, često se spominje plodonosna kombinacija sa vršnjačkom procenom (engl. peer evaluation, Panadero et al., 2016b). U svojoj doktorskoj disertaciji Gligorić iznosi mišljenje da nastavnik nije (i ne treba da bude) izopšten iz procesa učeničke samoprocene, već da ima ulogu medijatora (2018: 29). U tom smislu, ova autorka govori o kolaborativnoj evaluaciji, koja počiva na interakciji učenika i nastavnika (ibid., 30).

Što se tiče tehničke strane samoprocene, odnosno, samih instrumenata, najjasniju klasifikaciju dali su Panadero i saradnici (premda ni ona nije savršena). Osnovni parametar njihove tipologije je forma kriterijuma za samoprocenu. Tako su oni uočili tri formata instrumenata (Panadero et al., 2016a: 6):

1) bez eksplicitnog kriterijuma 
2) rubrika (engl. rubric)

3) skript (engl. script)

Prvi tip je najslabije definisan, po svoj prilici zato što je najmanje strukturiran, dok je ostalim formatima posvećeno dosta pažnje. Tome u prilog ide zaključak istraživanja koje su sproveli Panadero i Romero (Panadero \& Romero, 2014; in Panadero et al., 2016b: 318) - da je vođena (instrumentalizovana) samoprocena plodonosnija od one u kojoj nije ekspliciran kriterijum (,intuitivne“, nestrukturirane).

Rubrike sadrže kriterijum sa jasno opisanim standardima kvaliteta i skalu procene. Određen broj poena na skali odgovara određenoj meri u kojoj je ispunjena zadata norma (Panadero \& Alonso-Tapia, 2013: 567-568). Braun i Haris smatraju da skala (tj. skor) nije obavezan element, za razliku od deskriptora kvaliteta (Brown \& Harris, 2013: 370).

Skript $^{7}$ se može definisati kao ,lista konkretnih pitanja čiji redosled odgovara koracima koje bi odličan poznavalac date oblasti preduzeo za rešavanje zadatog problema“"8 (Panadero et al., 2016b: 317). Iz ove definicije može se naslutiti da skript nije autoevaluacioni instrument per se, što uostalom potvrđuju i sami autori: „Svrha skripta je da podstakne razmišljanje o opravdanosti radnji koje se vrše i o parcijalnim rezultatima dobijenim tokom rada na samom zadatku“9 (Panadero \& Alonso-Tapia, 2013: 569). Drugim rečima, učenici odgovaraju (obično sa „da/ne“) na pitanja koja u sebi sadrže kriterijum. Odgovori mogu biti očigledan indikator njihovog napretka, ali sam koncept skripta osmišljen je prevashodno kao podsetnik („memento“). Stoga ćemo u nastavku termine skript i ček lista koristiti kao sinonime.

Pored ovih instrumenata, postoji širok dijapazon samoprocenjivačkih tehnika. Braun i Haris navode Klarkove primere otvorenih pitanja/naloga poput: „Dve stvari u kojima sam napredovao/la su...“ ili „Sledeći put moram obratiti više pažnje na..." (Clarke, 2005: 113; in Brown \& Harris, 2013: 369).

\section{$7 \quad$ Gligorić (2018: 57) koristi termin skripta.}

8 Naš prevod sa engleskog: ,[A] list of specific questions, structured in steps that model how an expert in the field would approach a complex task from beginning to end". 9 Naš prevod sa engleskog: „The purpose of scripts is to promote reflection on the adequacy of the process that is being followed, and on the partial results that are being obtained during the performance of the task". 
Pored pomenutih eksplicitnih poziva na samoprocenu, smatramo da udžbenici mogu i na implicitan način podsticati učenika, o čemu svedoči primer koji smo našli u radu prof. Končarević. Naime, proučavajući korpus metoda ruskog jezika koje se koriste u različitim zemljama autorka je u onim koje koriste učenici u Slovačkoj uočila grafičko obeležje stepena težine nekog zadatka - na primer, broj zvezdica (Кончаревић 2008 : 52).

\section{Analiza korpusa}

Naš korpus sastoji se iz tri udžbenika za učenje francuskog jezika namenjenih odrasloj publici i starijim adolescentima. Odabrali smo početni nivo učenja da bismo videli da li udžbenici sadrže funkciju učeničke samoprocene u najranijem stadijumu. Analizirali smo udžbenik kao osnovno sredstvo nastave i učenja. Naše istraživanje počiva na parametrima koje smo predstavili u teorijskom delu rada.

Sva tri udžbenika rađena su prema preporukama ZEOJ-a i postulatima akcione perspektive. Alter Ego Al objavljen je 2006. godine, Nouveau Rond-Point pas à pas A12010, dok je ovo izdanje udžbenika Edito Al iz 2016. godine. Kriterijum za odabir metoda bila je, prevashodno, činjenica da se sve tri knjige često koriste (prema nezvaničnim podacima, iskustvima nastavnika i učenika u svetu i kod nas, ali i iz našeg ličnog iskustva). Želeli smo da vidimo u kojoj meri ,poznati“ udžbenici neguju funkciju učeničke samoprocene i učestvuju u građenju učenikove autonomije.

\subsection{Analiza udžbenika Alter Ego A1}

Alter Ego A1 (u nastavku koristićemo siglu AE1), počev od trećeg modula (fr. dossier), sve do poslednjeg, devetog, posvećuje pažnju učeničkoj samoproceni. Struktura tih delova je ista za svaku nastavnu celinu, ali smo uočili da je uvođenje u tematiku samoprocene i metakognicije postepeno. Na kraju svakog od pomenutih modula (AE1, 2006: 64, 80, 96, $112,128,144,160)$ nalazi se strana naslovljena kao Shvatite i primenite ${ }^{10}$ podeljena na dve celine. Prva polovina svake strane obrađuje konkretno gradivo koje je učenik prešao u datom modulu kroz dve aktivnosti. Prva aktivnost uvek se tiče govornih činova koji su obrađeni u njemu. Učenik treba da štiklira one govorne činove sa kojima se susreo. Međutim, zani-

10 Naš prevod sa francuskog: Comprendre pour agir. 
mljiv je rečnik samog naloga - kada se učenik na kraju trećeg modula prvi put susreće sa pozivom na samorefleksiju, nalog glasi: „Šta ste otkrili u ovom modulu?"“11, a neki od ponuđenih odgovora su ,predložiti nekome neku aktivnost, zakazati sastanak“" (AE1, 2006: 64). U potonjim modulima nalog implicitno ukazuje na učenikov napredak: „Šta ste naučili da radite u ovom modulu?"12 (ibid., 80, 96, 112, 128, 144, 160).

U strukturi druge aktivnosti takođe je očigledna gradacija. Cilj je da učenik ume da poveže odgovarajuće delove gradiva sa lekcijom i zadatkom u kojima su oni obrađeni. Po završenom trećem modulu, učeniku se taj nalog daje direktno: „Na kojim mestima u knjizi izvodite sledeće aktivnosti?"13. Na primer, pored govornog čina ,govoriti o svom karakteru" treba upisati broj odgovarajuće lekcije i vežbanja (ibid., 64). Smatramo da ovako formulisan nalog služi prevashodno da se učenik upozna sa strukturom samog udžbenika i da se inicira u ,znanja o zadatku“ (Кончаревић, 2006: 8-11). Naredni moduli sadrže drugačije formulisan nalog, čime se značajno menja perspektiva. Uzmimo kao primer peti modul. Od učenika se traži da obeleži one lekcije i zadatke koji su mu pomogli da nauči kako da se javi na telefon, kako da govori o porodici itd (AE1, 2006: 96). Treći, inicijalni modul bavio se „tehničkom“" stranom udžbenika, a kada se učenik upoznao sa elementima udžbeničke tekstoteke, prešlo se na promišljanja o metakognitivnim strategijama.

Druga polovina strane eksplicitno je posvećena autoevaluaciji i takođe sadrži dve aktivnosti. Prva ima oblik tipične ček liste u kojoj učenik obeležava da li jeste ili nije savladao određenu komunikativnu aktivnost (termin upotrebljen u trećem modulu, ibid., 64), odnosno savoir-faire (termin upotrebljen u svim potonjim modulima). Razlika između ova dva termina može (premda ne nužno) biti značajna učeniku, budući da savoirfaire označava „umeća“, to jest kompleksna znanja koja podrazumevaju kombinovanu upotrebu veština (ZEOJ, 2002: 40). Deskriptori, poput onih u ZEOJ-u, počinju sa „mogu da...“, npr. „Mogu da govorim o vremenskim prilikama" (AE1, 2006: 112). Aktivnost je koncipirana tako da se učenik prvo samoproceni, nakon čega treba da uradi test koji mu da nastavnik. Na

11 Naš prevod sa francuskog: „Quelles sont vos découvertes dans ce dossier?“.

12 Naš prevod sa francuskog: „Qu'est-ce que vous avez appris à faire dans ce dossier?".

13 Naš prevod sa francuskog: „Où faites-vous ces activités dans le livre?“. 
kraju treba da uporedi svoje viđenje sa nastavnikovom procenom i ubeleži datum kada je pokazao da može da uradi ono što je naznačeno u deskriptorima. Zbog prisustva poslednjeg elementa ovaj instrument ima odliku dnevnika učenja. U analizi ove ček liste osvrnuli bismo se na dve pojave. Prvo, autori udžbenika ne govore ništa o slučaju u kojem se učenikova i nastavnikova procena ne poklapaju, čime se izbegava pitanje validnosti samoprocene, koje je, kao što smo videli u teorijskom delu, uvek otvoreno. Takođe nam je bio zanimljiv afirmativan stav autora prema učenikovom napretku. Naime, u ček listi nije ponuđen odgovor „nisam savladao/la“. Končarević, kao što smo videli, smatra da bi metode trebalo da sadrže rubriku „,ne znam“ ili „ne razumem“, kako bi učenik imao jasnu predstavu o onome što je savladao i o onome što mu tek predstoji (Кончаревић, 2006: 12).

Najzad, poslednja aktivnost je identična za svaki modul (AE1, 2006: $64,80,96,112,128,144,160)$ i logički proizilazi iz prethodne. Od učenika se traži da nakon testa pita nastavnika kojim tipovima veština i vežbi treba da posveti pažnju kako bi usvojio ono što je u ček listi označio kao problematično. Ponuđeni odgovori podrazumevaju: vežbe usmenog/pisanog razumevanja, usmene/pisane produkcije, gramatička ili fonetska vežbanja, vokabular, ili pak nešto drugo što udžbenik nije predvideo, čime se ostavlja sloboda nastavniku i učeniku da ponude neko rešenje. Osim toga, udžbenik nenametljivo, ali postojano podstiče interakciju između učenika i nastavnika. Smatramo da je ovaj primer ilustracija uspešne realizacije didaktičkog potencijala trijade učenik-nastavnik-udžbenik, budući da učenik gradi autonomiju i preuzima odgovornost za svoje učenje služeći se smernicama koje predlaže metoda, dok nastavnik u tom procesu ostvaruje ulogu medijatora. Čitava aktivnost počiva na povratnim informacijama koje učenik i nastavnik pružaju jedan drugom. Budući da udžbeničke aktivnosti samoprocene ne nude kriterijume uspešnosti ni u jednom vidu, oni bi trebalo da se konstruišu u dijalogu učenika i nastavnika.

\subsection{Analiza udžbenika $E$ dito $A 1$}

Édito Al (u nastavku ćemo koristiti siglu E1) ne sadrži funkcije samoprocene. Ipak, sadrži elemente ,znanja o strategijama“ (termin koji smo sreli u: Кончаревић, 2006: 12-13) koji su vezani za samoprocenu. Udžbenik E1 na kraju svakog drugog modula nudi strategije za polaganje 
DELF A1 ispita (2016: 46, 74, 102, 158). Reč je o praktičnim savetima za svaku od veština koje se proveravaju na ovom ispitu: razumevanje odslušanog i pročitanog teksta, kao i pisana i usmena produkcija. Strategije koje nudi ovaj udžbenik potpuno su u skladu sa njegovim sadržajima, budući da je jedan od njegovih ciljeva spremanje učenika za DELF, kao što je navedeno u predgovoru (ibid., 3). Međutim, smatramo da bi bilo dobro da strategije ne budu usredsređene samo na ispit DELF. Što se tiče globalnih paratekstualnih elemenata usko vezanih za samoprocenu, E1 ima zasebnu uvodnu stranu za svaki od modula (ibid., 19, 33, 47, 61, 75, 89, 103, 117, $131,145,159,173)$. Uvodne strane su vizuelno obogaćene autentičnim ilustracijama i sadrže kratak spisak onoga što učenika očekuje u nastavku. Na primer, u trećem modulu učenik će naučiti da kupuje hranu, poruči u restoranu i govori o onome što voli/ne voli (ibid., 47).

\subsection{Analiza udžbenika Nouveau Rond-Point pas à pas A1}

Poput E1, ni ovaj udžbenik (u nastavku ćemo koristiti siglu NRP) ne sadrži funkcije samoprocene, ali nudi ,znanja o strategijama“. Naime, NRP u prva četiri modula sadrži po dva saveta vezana za učenje jezika uopšte. Na primer, učeniku se objašnjava kako i u kojim slučajevima treba koristiti rečnik (NRP, 2010: 35), ili mu se skreće pažnja na to koliko je važna motivacija za učenje jezika (ibid., 19). Takvi saveti su dragoceni, naročito za početnika u učenju jezika, ali bilo bi dobro da je udžbenički metakognitivni potencijal ostvaren do kraja pomoću funkcije samoprocene.

Svaki modul sadrži najavu, kao i u slučaju prethodna dva udžbenika. Međutim, te uvodne strane u NRP su specifične jer otkrivaju samo finalni cilj modula - recimo: „Napravićemo intervju sa drugom iz odeljenja“ (ibid., 39) - ne eksplicirajući šta je sve potrebno savladati da bi se do tog cilja došlo. Pored toga, uvodne strane su bazirane na aktivnostima razumevanja, produkcije itd. u cilju uvođenja leksike koja će se provlačiti kroz čitav modul. Smatramo da bi bilo dobro kada bi postojala komplementarna aktivnost samoprocene na kraju te nastavne celine ili u toku samog rada na njoj. Budući da moduli počivaju na konkretnim kompleksnim zadacima, kao što je „organizovati tematsku žurku“ (ibid., 59), samoprocena bi se mogla odnositi na to kako je učenik koristio znanja o jeziku da realizuje ono što se od njega zahtevalo. 


\subsection{Rezultati}

Kao i svi savremeni udžbenici sa kojima smo se susretali, NRP, E1 i AE1 sadrže najave modula koji ekspliciraju učeniku šta će u njima naučiti. Međutim, za razliku od AE1, ostala dva udžbenika ni na koji način ne upućuju učenika na samoprocenu. Premda sadrže veoma važnu komponentu - znanja o strategijama - smatramo da ona ne može realizovati svoj pun potencijal ako nije upotpunjena autoevaluacionom funkcijom. S druge strane, AE1 takođe sadrži neka pitanja strategija učenja, ali ne nudi eksplicitnu instrukciju o tome kako bi učenik trebalo nešto da radi. Naprotiv, AE1 podstiče učenika i nastavnika da o tome zajedno promišljaju. Funkciju samoprocene i ostalih metaznanja koje smo uočili u korpusu prikazaćemo u Tabeli I.

Sva tri udžbenika sadrže najave modula i sadržaja u njima, kao i različite strategije. NRP daje savete za učenje jezika uopšte, dok je E1 koncentrisan na pripremu učenika za polaganje DELF-a, i stoga se bavi strategijama u vezi sa aktivnostima koje su tipične za ovaj ispit. AE1 podstiče učenika da promišlja o strategijama učenja u okviru specifičnih aktivnosti (razumevanja govora, usmene produkcije i sl.). Osim toga, strategije u AE1 su inkorporirane u autoevaluacione sadržaje, što bismo okarakterisali kao kvalitetno konstrukcijsko rešenje. S druge strane, u NRP i E1 je uočljivo da jedna metakognitivna komponenta (strategije) dominira nauštrb druge (samoprocene), te smatramo da je odsustvo autoevaluacionih funkcija ozbiljan nedostatak koji treba ispraviti u narednim izdanjima udžbenika. Zanimljivo je da se ta (a)simetrija preslikava i u komponenti koja je implicitno povezana sa samoprocenom - a to su uvodne stranice modula. Najave u AE1 sadrže listu svih govornih činova za dati modul raspoređenih onim redom kojim se javljaju u lekcijama. Kada učenik na kraju modula radi aktivnosti vezane za samoprocenu i strategije, uvodna strana može da mu služi kao podsetnik (uostalom, ovo konstrukcijsko rešenje oslikava koheziju udžbenika). Za razliku od AE1, najave u NRP i E1 nisu tako čvrsto strukturirane. Uvodnu stranu u E1 čini karikatura ili ilustracija kao lajtmotiv datog modula, a u dnu se nalaze govorni činovi koji će se obrađivati. NRP čak ni ne sadrži govorne činove u najavnom delu, već opisuje finalnu aktivnost predviđenu za taj modul i na licu mesta daje vežbe koje služe za „zagrevanje“" i inicijaciju u tu tematiku. 
Najzad, budući da AE1 poseduje izrazite autoevaluacione funkcije, njih smo popisali i analizirali sa posebnom pažnjom. U Tabeli II dat je grafički prikaz modaliteta samoprocene u ovom udžbeniku. Naša analiza je pokazala da su autori AE1 pažljivo osmislili realizaciju učeničke samoprocene, ali je očigledno da su ostavili veliki prostor nastavniku i samom učeniku, budući da je njihov feedback osnova za njeno sprovođenje. AE1 direktno poziva učenika na samoprocenu koristeći strukturirane instrumente. Samoprocena se sprovodi redovno na kraju svakog modula, počev od trećeg. Primetno je da se učenik uvodi postepeno u mehanizme samoprocene i metakognitivna razmatranja. Obuhvaćene su četiri jezičke veštine (pisana i usmena produkcija i razumevanje), kao i sva tri tipa metaznanja. Prvo se radi na znanjima o zadatku, to jest, o tome šta je trebalo da se nauči kroz date lekcije. Zatim se učeniku daje prilika da proceni svoje sposobnosti kroz različite segmente gradiva i da uporedi svoju procenu sa nastavnikovom. Pored toga, udžbenik ga podstiče da vodi dnevnik svojih uspeha u učenju, čime pozitivno utiče na motivaciju i samopouzdanje. Na kraju, učenik se kroz konsultaciju sa nastavnikom upoznaje sa metakognitivnim strategijama. U ovoj metodi samoprocena je veoma zastupljena: od ukupno 192 strane, obrađuje je 7 strana (3,65\%).

\section{Zaključak}

U teorijskom delu našeg rada rasvetlili smo neke važne aspekte učeničke samoprocene. Pre svega, nastojali smo da što preciznije odredimo ono što samoprocena obuhvata i koji termini su najpodesniji da je imenuju. Zatim smo pokazali zašto je ona važna i zbog čega vlada konsenzus da se ona nađe u udžbenicima stranog jezika. Takođe smo se dotakli metakognicije, oblasti u koju samoprocena spada zajedno sa još nekim komponentama. Na kraju smo se bavili njenim modalitetima i načinima na koje ona može biti inkorporirana u udžbenik.

Naša analiza je pokazala da se sadržaj nekih udžbenika ne poklapa sa zahtevima i preporukama savremene teorijske paradigme. Uprkos činjenici da su udžbenici iz našeg korpusa razvijeni u skladu sa preporukama ZEOJ-a i savremenim tendencijama u glotodidaktici, oni ne razvijaju funkcije učeničke samoprocene u podjednakoj meri. S jedne strane je Alter Ego Al, u kojem autoevaluacija zauzima vrlo značajno mesto. 
Takođe, naša analiza je pokazala da su autori pitanju samoprocene pristupili vrlo temeljno i planski. S druge strane, udžbenici Edito Al i Nouveau Rond-Point Al ne nude autoevaluacione sadržaje, premda se bave „znanjima o strategijama“ i ,znanjima o zadatku“ koja su, gledano iz šire perspektive, povezana sa samoprocenom. Edito Al orijentisan je na strategije polaganja DELF A1 ispita, dok se Nouveau Rond-Point bavi tehnikama koje olakšavaju učenje jezika uopšte. Međutim, smatramo da učenik ne može imati celovitu sliku o svojim znanjima i mogućnostima, niti može razvijati autonomno učenje sve dok mu se ne ponudi mogućnost samoprocene.

\section{LITERATURA}

Bertocchini, P. \& Costanzo, E. (2017). Manuel de formation pratique pour le professeur de FLE : cours, activités, corrigés. Paris: CLE international.

Blue, G. M. (1994). Self-Assessment of Foreign Language Skill: Does It Work?. CLE Working Papers, $n^{\circ} 3$, 18-35. Dostupno preko: https://eric. ed.gov/?id=ED396569 [10.4.2019.]

Brown, G. T. L. \& Harris, L. R. (2013). Student Self-Assessment. In J. McMillan (ed), The SAGE handbook of reserach on classroom assessment (pp. 367393). Thousand Oaks, CA: SAGE.

Butler, Y. G. \& Lee, J. (2006). On-Task Versus Off-Task Self-Assessments Among Korean Elementary School Students Studying English. The Modern Language Journal, 90, iv, 506-518. [on-line]. Dostupno preko: https://onlinelibrary.wiley.com/doi/abs/10.1111/j.1540-4781.2006.00463.x [10.4.2019.]

Clarke, S. (2005). Formative assessment in the secondary classroom. Abingdon, UK: Hodder Murray.

Dickinson, L. (1987). Self-instruction in Language Learning. Cambridge: Cambridge University Press.

Gligorić, S. (2018). Razvoj učeničke autonomije: gradiranje zadataka za samoevaluaciju u udžbenicima engleskog kao stranog jezika na nivou osnovne škole (neobjavljena doktorska disertacija). Filološki fakultet, Beograd. [on-line]. Dostupno preko: https://phaidrabg.bg.ac.rs/detail_object/ o:19306?tab=0\#mda [10.4.2019.]

Holec, H. (1979). Autonomie et apprentissage des langues étrangères. Paris: Hatier. 
Kankaraš, M. (2004). Metakognicija - nova kognitivna paradigma. Psihologija, vol. 37 (2), 149-161. [on-line]. Dostupno preko: https://scindeks-clanci.ceon.rs/data/pdf/0048-5705/2004/0048-57050402149K. pdf\#search $=\% 22$ Inteligencija $\% 22$ [19. 2. 2019.]

Oskarsson, M. (1989). Self-Assessment of language proficiency: rationale and applications. Language Testing 6.1, 1-13.

Panadero, E. (2011). Instructional help for self-assessment and self-regulation: Evaluation of the efficacy of self-assessment scripts vs. rubrics. (neobjavljena doktorska disertacija). Department of Educational and Developmental Psychology, Universidad Autónoma de Madrid, Spain.

Panadero, E. \& Alonso-Tapia, J. (2013). Self-assessment: Theoretical and Practical Connotations. When it Happens, How is it Acquired and what to do to Develop it in our Students. Electronic Journal of Research in Educational Psychology, 11(2), $n^{\circ}$ 30, 551-576. [on-line]. Dostupno preko: http://ernestopanadero.es/ernesto-panadero-curriculum.html [27.1.2019.]

Panadero, E., Brown, G. T. L. \& Strijbos, J-W. (2016a). The future of student self-assessment: A review of known unknowns and potential directions. Educational Psychology Review, 28(4), 803-830. [on-line]. Dostupno preko: https://researchspace.auckland.ac.nz/handle/2292/317721 [2.2.2019.]

Panadero, E., Jonsson, A. \& Strijbos, J-W. (2016b). Scaffolding Self-Regulated Learning Through Self-Assessment and Peer Assessment: Guidelines for Classroom Implementation. In D. Laveault \& L. Allal (ed). Assessment for Learning: Meeting the Challenge of Implementation, The Enabling Power of Assessment 4 (pp. 311-327). Springer Switzerland. DOI 10.1007/978-3319-39211-0_18

Panadero, E. \& Romero, M. (2014). To rubric or not to rubric? The effects of selfassessment on self-regulation, performance and self-efficacy. Assessment in Education: Principles, Policy \& Practice, 21(2), 133-148.

Papanthymou, A. \& Darra, M. (2019).The Contribution of Learner Self-Assessment for Improvement of Learning and Teaching Process : A Review. Journal of Education and Learning, Vol. 8, No. 1, Canadian Center of Science and Education, 48-64. [on-line]. Dostupno preko: https://eric.ed.go $\mathrm{v} / ? \mathrm{q}=$ maria + darra\&id=EJ1202130 [16.2.2019.] DOI 10.5539/jel.v8n1p48

Paris, S. G. \& Paris, A. H. (2001). Classroom applications of research on selfregulated learning. Educational Psychologist, 36(2), 89-101.

Pešikan, A. \& Antić, S. (2016). Zadaci u nastavi: kako da vaši učenici/studenti bolje napreduju u učenju.Beograd: Obrazovni forum, (Novi Beograd: Rebox). [on-line]. Dostupno preko: https://arhiva.nara.ac.rs/handle/123456789/2028 [16.2.2019.] 
Ross, J. A. (2006). The Reliability, Validity, and Utility of Self-Assessment. Practical Assessment, Research \& Evaluation, 11(10), 1-13. [on-line]. Dostupno preko: https://pareonline.net/getvn.asp? $\mathrm{v}=11 \& \mathrm{n}=10$ [16.2.2019.]

Taglijant, K. (2009). Evaluacija i Zajednički evropski okvir. Beograd: Data Status. Veltcheff, C. \& Hilton, S. (2003). Evvaluation en FLE. Paris: Hachette.

Zajednički evropski okvir za učenje, nastavu i ocjenjivanje jezika. (2002). Podgorica: Ministarstvo prosvjete i nauke. [ZEOJ]

Zimmerman, B. J. \& Moylan, A. R. (2009). Self-regulation: Where metacognition and motivation intersect. In: D. J. Hacker, J. Dunlosky, \& A. C. Graesser (ed), Handbook of Metacognition in Education (pp. 299-315). New York: Routledge.

Žiropađa, Lj. (2008). Samoevaluacija u nastavi stranih jezika. In J. Vučo (ur.), Evaluacija u nastavi jezika i književnosti (pp. 15-21). Nikšić: Univerzitet Crne Gore, Filozofski fakultet

Вујовић, А. (2009). Евалуација и самоевалуација у настави страног језика. Иноваиије у настиави, XXII, 2009/3. Београд: Учитељски факултет, 99106. [on-line]. Доступно преко: http://www.inovacijeunastavi.rs/wp-content/uploads/arhiva/2009/Inovacije-03_09.pdf [27.1.2019.]

Вујовић, А. (2016). Самоевалуација у уџбеницима француског језика у првом циклусу основног образовања. In Z. Kašić (ur.), O jeziku i jezicima primenjena lingvistika u čast Dušanki Točanac (pp. 337-351). Novi Sad - Beograd: Društvo za primenjenu lingvistiku Srbije. [on-line]. Доступно преко: http://dpls-alas.rs/pdf/Zbornik\%20D_Tocanac.pdf [27.1. 2019.]

Дурбаба, О. (2011). Теорија и ирракса учења и насииаве сиираних језика. Београд: Завод за уџбенике.

Кончаревић, К. (2008). Аутоконтрола, аутокорекција и аутоевалуација ученика посредством уџбеника страног (руског) језика: теоријски принципи и конструкцијска решења. In J.Vučo (ur.), Evaluacija u nastavi jezika i književnosti (pp. 45-55). Nikšić: Univerzitet Crne Gore, Filozofski fakultet.

Кончаревић, К. (2006). Метазнања у уџбенику страног језика. Иноващије у

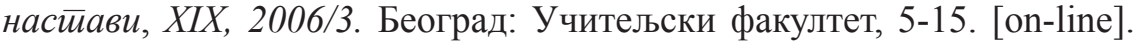
Доступно преко: http://www.inovacijeunastavi.rs/wp-content/uploads/arhiva/2006/INOVACIJE_3_06.pdf [27. 1. 2019.]

Кузмановић, Д. \& Павловић Бабић, Д. (2011). Приступи процењивању об-

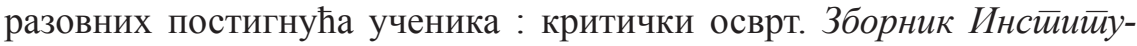
$\bar{u} а$ за иееgайошка истираживаға. Година 43, број 1. Београд: Институт 
за педагошка истраживања, 63-85. [on-line]. Доступно преко: http:// www.ipisr.org.rs/Upload/Dokumenta/Strane/ZbornikInstituta/43(1)2011/ Zbornik-10-104.pdf [27. 1. 2019.] DOI 10.2298/ZIPI1101063K

\section{Izvori}

Alcaraz, M., Braud, C., Calvez, A., Cornuau, G., Jacob, A., Pinson, C.\& Vidal, S. (2016). Édito A1 : méthode de français. Paris: Éditions Didier. [E1]

Berthet, A., Hugot, C., Kizirian V. M., Sampsonis, B. \& Waendendries, M. (2006). Alter Égo A1 : méthode de français. Paris: Hachette. [AE1]

Labascoule, J., Lause, C. \& Royer, C. (2011). Nouveau Rond-Point pas à pas A1 : livre de l'élève. Paris: Éditions Maison des langues. [NRP]

\section{Jelena P. Stojanović}

\section{LES MODALITÉS DE L'AUTOESTIMATION DANS LES MANUELS DU FLE AU NIVEAU A1}

\section{Résumé}

Dans notre travail, nous avons examiné les mesures et les formes sous lesquelles certaines méthodes du FLE poussent l'apprenant à s'autoévaluer. Nous avons opté pour trois méthodes des maisons d'édition françaises aboutissant au niveau A1 selon le Cadre européen commun, tout en gardant en esprit les recommandations des auteurs contemporains considérant l'autoestimation comme une compétence qui est maitrisée graduellement, dès le début de l'apprentissage. La première partie de notre travail traite le cadre théorique de l'autoestimation d'apprenant, tandis que la seconde partie consiste en étude du corpus. Notre analyse a montré que tous les trois manuels stimulent une forme de métacognition, mais qu'il n'y a qu'un seul orienté vers le développement de l'autoestimation d'apprenant et des soidisant « connaissances sur soi ». C'est la raison pour laquelle nous avons minutieusement examiné les modalités de l'autoestimation proposées dans cet ouvrage. Nous concluons que les méthodes de langue étrangère devraient considérablement pousser l'apprenant à l'autoréflexion et à l'autoestimation.

Mots-clés: autoestimation, autoévaluation, manuels du FLE 
MODALITETI SAMOPROCENE U UDŽBENICIMA FRANCUSKOG ...

\section{Prilozi}

\begin{tabular}{|c|c|c|c|}
\hline $\begin{array}{c}\text { Korpus } \\
\text { Znanja }\end{array}$ & Samoprocena & $\begin{array}{c}\text { O zadatku (najave } \\
\text { lekcija) }\end{array}$ & O strategijama \\
\hline$A E 1$ & $\mathrm{Da}$ & $\mathrm{Da}$ & $\begin{array}{c}\text { Da (specifične } \\
\text { aktivnosti) }\end{array}$ \\
\hline$E 1$ & $\mathrm{x}$ & $\mathrm{Da}$ & Da (DELF) \\
\hline$N R P$ & $\mathrm{x}$ & $\mathrm{Da}$ & $\begin{array}{c}\text { Da (učenje jezika } \\
\text { uopšte) }\end{array}$ \\
\hline
\end{tabular}

Tabela I : Tipovi metaznanja u našem korpusu.

\begin{tabular}{|c|c|c|c|c|c|c|c|}
\hline \multirow{8}{*}{ Glo- } \\
balna \\
$\begin{array}{c}\text { ili spe- } \\
\text { cifična }\end{array}$ & $\begin{array}{c}\text { Ekspli- } \\
\text { citna ili } \\
\text { impli- } \\
\text { citna }\end{array}$ & $\begin{array}{c}\text { Kombi- } \\
\text { nacija sa } \\
\text { vršnjač- } \\
\text { kom ili } \\
\text { nastav- } \\
\text { nikovom } \\
\text { procenom }\end{array}$ & $\begin{array}{c}\text { Veštine } \\
\text { koje se } \\
\text { proce- } \\
\text { njuju }\end{array}$ & $\begin{array}{c}\text { Strukturira- } \\
\text { nost instru- } \\
\text { menta }\end{array}$ & $\begin{array}{c}\text { Frekven- } \\
\text { cija u } \\
\text { udžbeni- } \\
\text { ku }\end{array}$ & $\begin{array}{c}\text { Mesto } \\
\text { u udž- } \\
\text { beniku }\end{array}$ \\
\hline $\begin{array}{c}\text { Obe } \\
\text { vrste }\end{array}$ & $\begin{array}{c}\text { Ekspli- } \\
\text { citna }\end{array}$ & $\begin{array}{c}\text { Nastav- } \\
\text { nička }\end{array}$ & $\begin{array}{c}\text { Sve osim } \\
\text { pisane i } \\
\text { usmene } \\
\text { medijaci- } \\
\text { je i inte- } \\
\text { rakcije }\end{array}$ & Strukturiran & $3,65 \%$ & $\begin{array}{c}\text { Na kra- } \\
\text { ju odre- } \\
\text { denih } \\
\text { modula }\end{array}$ \\
\hline
\end{tabular}

Tabela II: Modaliteti samoprocene u udžbeniku AE1. 